\title{
Metoda oceny stabilności układu łuk - urządzenie zasilające na podstawie przebiegów prądowo-napięciowych
}

\author{
Method of welding power supply - arc system \\ stability assessment based on voltage-current \\ waveforms
}

\section{Streszczenie}

Zjawiska fizyczne zachodzące w łuku podczas spawania różnymi odmianami metody MAG zależą między innymi od parametrów elektrycznych układu źródło zasilania - łuk. W artykule przedstawiono nową metodę badań i oceny stabilności układu źródło zasilania - łuk na podstawie zarejestrowanych przebiegów prądowo-napięciowych. Na drodze odpowiednich przekształceń, ściśle dostosowanych do konstrukcji badanego źródła zasilającego oraz odmiany metody MAG, możliwe jest uzyskanie cennych informacji charakteryzujących badany obwód, w tym np. pozwalających na identyfikację zakłóceń towarzyszących spawaniu, które w konsekwencji mogą doprowadzić do powstania niezgodności spawalniczych w złączu. W celu weryfikacji metody prowadzono badania w warunkach kontrolowanych, sztucznie wywoływanych zakłóceń przebiegu procesu z równoczesną rejestracją prądu spawania, napięcia łuku oraz obrazu przestrzeni łukowej z wykorzystaniem szybkiej kamery.

\section{Abstract}

The physical phenomena taking place in the arc column during various processes of MAG and MIG welding depend on both the welding conditions and the electrical parameters of power source-arc system. This paper presents a new method of an assessment of the stability of welding power supply-arc system based on voltage - current waveforms recorded during welding process. Transformations of the recorded waveforms assorted properly with the type of power supply and the kind of MAG welding process allows for acquiring information concerning any disturbances occurring in the welding circuit that might caused particular weld imperfections. In order to verify the proposed method a number of experiments has been carried on under controlled, artificially simulated disturbances of a welding process with simultaneous registration of current-voltage waveforms and pictures of the metal transfer modes across the arc column with the use of high-speed camera.

\section{Wstęp}

Badanie stabilności układu źródło zasilania - łuk na podstawie zarejestrowanych przebiegów prądowo-napięciowych może, metodą odpowiednich przekształceń, dostarczyć cennych informacji charakteryzujących

Mgr inż. Krzysztof Skrzyniecki, dr inż. Paweł Cegielski, dr hab. inż. Andrzej Kolasa, prof. PW, dr inż. Paweł Kołodziejczak - Politechnika Warszawska. badany obwód. Jednym z perspektywicznych obszarów praktycznego zastosowania może być monitorowanie procesu spawania połączone $z$ automatyczną identyfikacją zakłóceń, które mogą doprowadzić do powstania niezgodności spawalniczych w złączu. W ten sposób, zamiast choćby części konwencjonalnych badań już wykonanych połączeń, możliwe byłoby podjęcie działań korekcyjnych jeszcze w czasie spawania lub działań naprawczych ale w miejscach wstępnie zidentyfikowanych przez system monitorujący. 
W Zakładzie Inżynierii Spajania Politechniki Warszawskiej podjęto próbę opracowania nowych, możliwie obiektywnych metod badawczych i kryteriów oceny zarówno stabilności procesu spawania, jak i właściwości stosowanych urządzeń zasilających łuk. W wyniku szeregu przekształceń, ściśle dostosowanych do konstrukcji badanego źródła zasilającego oraz odmiany metody MAG, możliwe stało się uzyskanie takich informacji charakteryzujących badany obwód, które umożliwiają identyfikację zakłóceń towarzyszących spawaniu, mogących doprowadzić do powstania niezgodności spawalniczych w złączu. W celu weryfikacji metody prowadzono badania $w$ warunkach kontrolowanych, sztucznie wywoływanych zakłóceń przebiegu procesu z równoczesną rejestracją prądu spawania, napięcia łuku oraz obrazu przestrzeni łukowej $z$ wykorzystaniem szybkiej rejestracji $[3,6]$. W badaniach korzystano z wcześniej opracowanego i zbudowanego specjalistycznego stanowiska badawczego z komputerową rejestracją parametrów prądowo-napięciowych $[1,2,5,7]$.

W artykule szerzej omówiono zastosowane algorytmy i przekształcenia rejestrowanych sygnałów prądowo-napięciowych, odniesione do napawania łukowego wybranymi odmianami metody MAG.

Przedstawione w niniejszym artykule wyniki prac badawczych i konstrukcyjnych otrzymano podczas realizacji pracy naukowej finansowanej ze środków budżetowych na naukę w latach 2010-2013 jako projekt badawczy [4].

\section{Systemy monitorujące spawanie}

Na rynku można znaleźć komercyjne rozwiązania umożliwiające monitorowanie wybranych parametrów procesu spawania oraz porównywanie ich z założonymi poziomami tolerancji, przekroczenie których może być sygnałem do podjęcia odpowiednich działań korekcyjnych zgodnie z wymaganiami WPS. Z oczywistych względów algorytmy stosowane $w$ tego typu systemach nie są ujawniane. Ich wspólną cechą jest zbieranie i analiza sygnałów, które dla poprawnie, stabilnie przebiegającego procesu powinny pozostawać w zakresie tolerancji, a odchyłki od stałego poziomu poza granice tolerancji stanowią informację o potencjalnym zaburzeniu procesu. Jeżeli obserwowane parametry zmieniają się $\mathrm{w}$ trakcie procesu lub cechują się dużymi rozrzutami poprawnych wartości, niezbędne są dodatkowe filtry, które wygładzą przebieg, zbliżając je do formy ułatwiającej ocenę. Filtrowanie powoduje jednak utratę części danych, zawierających cenne informacje o przebiegu i jakości procesu. Poniżej omówiono kilka systemów monitorujących [8].

Weld Data Monitor (WDM) firmy ABB korzysta z narzędzi do automatycznej analizy wzorców spawania w korelacji z położeniem elektrody i pozycją spawania. Zastosowany algorytm porównuje charakter rejestrowanego przebiegu z bazowym wzorcem odpowiednim dla danego procesu. Wzorzec uzyskiwany jest na podstawie przechowywanych danych z przebiegów otrzymanych podczas wykonywania kilku spoin referencyjnych. System może monitorować do aż czterech wejść analogowych lub grupowych, nazywanych dalej kanałami pomiarowymi. Dane, zebrane dla każdego kanału, są przechowywane w plikach na dysku twardym. Zazwyczaj dwa kanały zarezerwowane są do rejestracji przebiegów napięcia łuku i prądu spawania, a dwa dodatkowe kanały pomocnicze są przeznaczone dla parametrów takich jak np.: prędkość posuwu drutu elektrodowego, wydatek gazu osłonowego lub moment obrotowy silnika posuwu uchwytu elektrody. Zakres zastosowań pakietu WDM może być wyznaczony jedynie na podstawie testów empirycznych, podczas wykonywania złączy produkcyjnych, z użyciem konkretnego osprzętu spawalniczego, a jego wyniki w dużej mierze są uzależnione od jakości rejestrowanych sygnałów pomiarowych oraz od jakości przebiegu samego procesu. Zastosowanie systemu WDM dotyczy trzech podstawowych odmian procesu MIG/MAG:

- Łuk natryskowy dostarcza idealnych danych dla systemu, które pozwalają wykryć i bardzo małe odchyłki parametrów procesu od wartości referencyjnych. Sygnały pomiarowe mogą być zbierane bezpośrednio z systemów sterowania zasilaczami spawalniczymi, bez konieczności instalowania dodatkowych czujników.

- Proces spawania ze zwarciowym przechodzeniem metalu jest trudny do monitorowania ze względu na duże wahania rejestrowanych sygnałów, zarówno prądu, jak i napięcia. W tym przypadku konieczne jest zastosowanie dodatkowych, zewnętrznych układów, odpowiednio filtrujących rejestrowane dane.

- Proces spawania łukiem zasilanym prądem pulsującym może również być monitorowany w celu wykrywania zakłóceń. Dane muszą być jednak wystarczająco odfiltrowane, aby wygładzić przebiegi prądu i napięcia pomiędzy poziomami maksymalnymi i minimalnymi impulsu. Jeżeli dane dostarczane przez spawalnicze źródło energii nie są odpowiednio filtrowane, niezbędne jest zastosowanie zewnętrznych układów filtrujących.

Rejestrator parametrów spawania RPS firmy SOMAR służy do monitorowania i rejestracji parametrów spawania wszystkimi podstawowymi metodami łukowymi. Rejestrator nie wymaga dodatkowych, zewnętrznych czujników do monitorowania parametrów podstawowych. Dane pobierane są bezpośrednio z układów pomiarowych i sterowniczych urządzenia spawalniczego poprzez dostępny interfejs komunikacyjny (CAN, RS-232, RS-422/485). Standardowo monitorowane są następujące parametry: natężenie prądu spawania, napięcie łuku elektrycznego, prędkość podawania drutu elektrodowego i objętościowe natężenie przepływu gazu osłonowego.

Dodatkowo rejestrator może być dostosowany do 
zbierania innych danych przesyłanych kanałem komunikacyjnym. Zainstalowane oprogramowanie RPSReader służy do odczytu, wizualizacji, przetwarzania, analizy oraz archiwizacji danych. Funkcje programu RPSReader umożliwiają :

- prowadzenie kartotek urządzeń rejestrujących,

- czytanie danych z urządzeń przez Ethernet, WiFi oraz nośniki danych USB,

- archiwizowanie danych na dysku komputera,

- przeglądanie zebranych plików rejestracji,

- sortowanie rejestracji w tabelach zbiorczych,

- przeglądanie poszczególnych plików rejestracji na wykresach czasowych,

- tworzenie rejestru technologicznych instrukcji spawania (WPS),

- prowadzenie oceny wstępnej na podstawie przyporządkowanych do spoin instrukcji WPS,

- tworzenie raportów statystycznych z rejestrowanych parametrów spawania, w tym czasu pracy.

Kolejny system - Weldoc 4000 firmy ESAB, przeznaczony jest do monitorowania, wizualizacji oraz archiwizacji parametrów procesu. Połączenie z urządzeniem spawalniczym odbywa się za pomocą magistrali wymiany danych. Konstrukcja urządzenia spawalniczego określa, jakie ustawienia i sygnały mogą być rejestrowane. Urządzeniom można nadawać indywidualne nazwy w celu lepszej identyfikacji zarejestrowanych parametrów i ich dopuszczalnych zakresów zgodnie z instrukcjami WPS. W przypadku spawania wielościegowego można zdefiniować przerwy czasowe w rejestracji parametrów, odpowiadające harmonogramowi wykonywania ściegów. Ma to na celu uniknięcie błędów spowodowanych wykrywaniem przekroczenia założonych limitów, podczas gdy proces spawania nie odbywa się w przerwach pomiędzy ściegami.

System monitorowania procesu spawania ARCAgent $^{\text {TM }}$ firmy IMPACT WELDING zaprojektowany został w celu monitorowania, w czasie rzeczywistym, przebiegu spawania łukowego. Wykorzystuje czujniki wbudowane w monitorowany sprzęt spawalniczy. Sygnały zebrane z czujników porównywane są z założonymi tolerancjami, dobranymi do każdego procesu. System pozwala wykrywać niestabilności procesu, zanim wpłyną one na jakość wyrobu. W momencie wykrycia niestabilności lub przekroczenia przyjętego zakresu tolerancji system wysyła sygnał alarmowy, a nawet może zatrzymać proces. Na bazie parametrów rejestrowanych przez system ARCAgent ${ }^{\mathrm{TM}}$ możliwa jest dalsza obróbka, wykorzystująca dodatkowe moduły funkcjonalne. Moduł Advanced Weld Signature ${ }^{\mathrm{TM}}$ Analysis zawiera cztery dodatkowe algorytmy analizy monitorowanego procesu porównywanie z przebiegami wzorcowymi. Może służyć zarówno do pomiarów, jak i wykrywania niestabilności oraz zakłóceń łuku. Moduł CAT Porosity Algorithm ma zdolność do wykrywania porowatości w monitorowanym złączu.

Odmiennie prezentuje się aplikacja Wave Designer firmy Lincoln Electric. Umożliwia ona przede wszystkim graficzną edycję kształtów przebiegu natężenia prądu zasilającego łuk spawalniczy. Wzorzec kształtu może być modyfikowany przez zmianę wybranych parametrów. Istnieją oczywiście wzajemne relacje pomiędzy modyfikowanymi parametrami, nakładające na nie pewne ograniczenia. System pełni zatem rolę edytora kształtu impulsu, co wskazuje na jego istotne znaczenie dla przebiegu procesu, a zarazem spełnia funkcję monitorowania na zasadzie programowego oscyloskopu (ArcScope). Ma do tego celu czujniki wbudowane w spawalnicze urządzenie zasilające. Pomiar może być uzupełniony o informacje nt. bieżących nastaw monitorowanego źródła zasilającego. Jednak w odróżnieniu od możliwości edycyjnych, funkcje monitorujące są znacznie uproszczone i działają na bazie uśredniania parametrów przebiegu.

\section{Warunki prowadzenia badań}

Program badań zakładał wykonanie szeregu napoin metodą MAG, zarówno w warunkach normalnych (proces nie był zakłócany), jak i podczas sztucznie wywoływanych zakłóceń przebiegu procesu, z równoczesną rejestracją prądu spawania, napięcia łuku oraz obrazu przestrzeni łukowej z wykorzystaniem szybkorejestrującej kamery. Spawano różnymi odmianami metody MAG (konwencjonalną bez pulsacji ze sterowaniem synergicznym, konwencjonalną bez pulsacji ze sterowaniem ręcznym, prądem pulsującym oraz odmianą niskoenergetyczną CMT), a także wykorzystując różne rodzaje źródeł zasilających (prostownik diodowy, źródła inwertorowe różnej generacji). Szerzej omówiono to we wcześniejszych publikacjach $[3,6]$.

Pomiar napięcia realizowano indukcyjnym przetwornikiem prądowym T60404-N4644-X053 firmy Vacumschmelze o zakresie pomiarowym do $500 \mathrm{~A}$, częstotliwości przenoszenia $50 \mathrm{kHz}$ i przełożeniu 1:2000. Do pomiaru napięcia wykorzystano specjalistyczny przetwornik LEM CV 3-200 o zakresie pomiarowym 200 V, częstotliwości przenoszenia $300 \mathrm{kHz}$ i współczynniku przełożenia 1:20. Dodatkowo zastosowano indywidualnie dobierane dzielniki napięcia, mające na celu dopasowanie sygnałów pomiarowych do zakresu dostępnego dla karty pomiarowej. Sygnały napięciowe zebrane zobydwu czujników rejestrowano przez kartę pomiarową NI PCI-6251 i zapisywano, w celu przyśpieszenia działania programu, w postaci nieprzetworzonej. Karta umożliwiała rejestrację 16 wejść analogowych z częstotliwością do $1 \mathrm{MS} / \mathrm{s}$ i 16-bitową rozdzielczością w zakresie do $10 \mathrm{~V}$.

\section{Wstępna obróbka danych}

Pierwszym etapem, obróbki zarejestrowanych danych było ich przeskalowanie w celu uzyskania rzeczywistych wartości prądu oraz napięcia. Zastosowano 
odwzorowanie liniowe reprezentowane wzorami:

$$
\begin{aligned}
& i(t)=100 \cdot v_{i}(t) \\
& u(t)=30 \cdot v_{u}(t)
\end{aligned}
$$

gdzie: $i(t)$ - rzeczywista wartość prądu; $u(t)$ - rzeczywista wartość napięcia; $V_{i}(t)$ - wartość napięcia z przetwornika prądu; $V_{u}(t)$ - wartość napięcia z przetwornika napięcia.

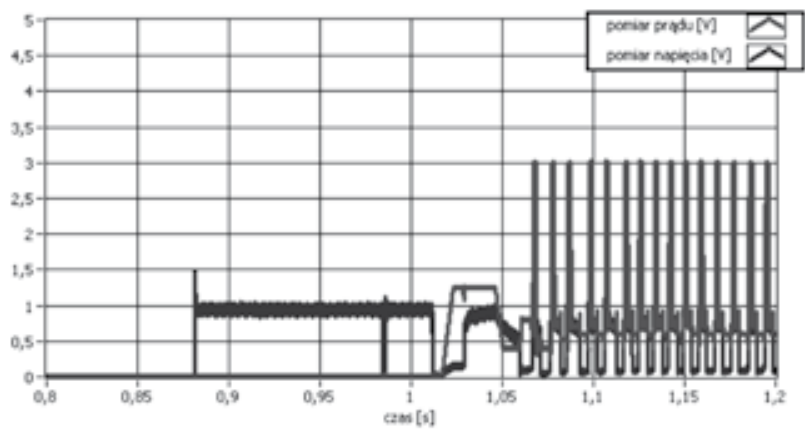

Rys. 1. Sygnały napięciowe z przetworników prądu i napięcia Fig. 1. Voltage and current signals recorded with the use of transducers

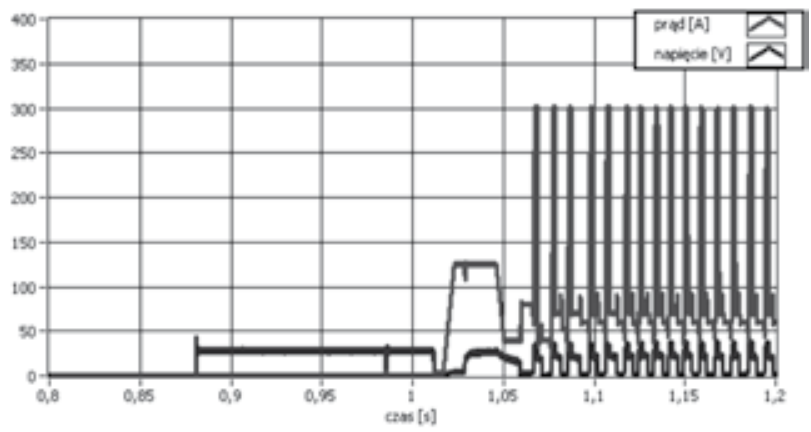

Rys. 2. Wyznaczone, rzeczywiste wartości prądu i napięcia

Fig. 2. The real, calculated values of current and voltage

Na rysunkach 1 i 2 przedstawiono zarejestrowane sygnały napięciowe z przetworników prądu i napięcia oraz ich wartości wyznaczone na drodze przekształcenia. Otrzymane wyniki zostały następnie poddane procesowi filtrowania dolnoprzepustowego, mającego na celu usunięcie z przebiegów efektów przełączeń tranzystorów (dotyczy badań zasilaczy z wewnętrznymi układami kluczującymi, np. źródeł inwertorowych). Dodatkowo, przebieg prądu ograniczono, eliminując wartości zerowe. W późniejszych obliczeniach rezystancji dynamicznej wartość prądu umieszczano w mianowniku, a więc wartości zerowe uniemożliwiałyby prawidłowe kalkulacje.

\section{Podsumowanie}

W wyniku opisanych w tym artykule badań oraz ich wyników potwierdzono wysoką przydatność opracowanego i wykonanego w ZIS PW układu pomiarowego z aplikacją pomiarowo-rejestrującą w środowisku LabView. Potwierdzono także skuteczność nowej metodyki wyodrębniania wartości skutecznych zarejestrowanych przebiegów prądowo - napięciowych w poszczególnych fazach jarzenia się łuku i przecho-

\section{Wyznaczanie wykresów wartości skutecznych}

Dalszego przetwarzanie danych umożliwiło wyznaczenie wartości skutecznych zarejestrowanych sygnałów, osobno dla momentów zwarcia i dla fazy jarzenia się łuku. Jako wyznacznik, odróżniający stan zwarcia od jarzenia łuku, przyjęto wartość rezystancji chwilowej. Poziom progu rozróżniającego wytypowano dla każdej z odmian spawania MAG (a także konstrukcji badanego źródła) na etapie badań wstępnych. Przedstawiono to na przykładzie spawania metodą CMT.

Wartość oporności chwilowej wyznaczono z prawa Ohma (3):

$$
R(t)=\frac{u(t)}{i(t)}
$$

gdzie: $R(t)$ - chwilowa wartość oporności; $u(t)$ - chwilowa wartość napięcia; $i(t)$ - chwilowa wartość prądu.

Szczegółowe przekształcenia prowadzono oddzielnie dla każdej z badanych odmian spawania MAG, m.in. ze względu na odmienny charakter rejestrowanych przebiegów [3, 6]. Wspólnym elementem przekształceń był podział przebiegu na przedziały czasowe odpowiadające fazom przechodzenia materiału w łuku spawalniczym, przeprowadzony na podstawie analizy poziomu oporności chwilowej. Tak wyznaczone przedziały stanowiły podstawę do wyznaczenia wartości skutecznych dla prądu i napięcia.

Wyodrębnione zostały trzy fazy: zwarcia, jarzenia łuku oraz wydłużonego łuku. W obrębie każdej z nich wyznaczono wartości skuteczne prądu i napięcia dla wszystkich cykli, a następnie naniesiono je na wykresy.

Przykładowe zestawienie wartości skutecznych, wyznaczonych osobno dla poszczególnych, wybranych faz cyklu przechodzenia materiału w łuku, przedstawiono na rysunkach 3 i 4, na przykładzie analizy sygnałów zarejestrowanych podczas spawania odmianą CMT ( Cold Metal Transfer).

Tablica I. Zakres oporności chwilowej odpowiadający fazom cyklu przechodzenia materiału w łuku, om

Table I. Applied resistance ranges for different phases of the cycle of metal transition in the arc, ohm

\begin{tabular}{|c|c|c|}
\hline Zwarcie & Jarzenie & Wydłużony łuk \\
\hline$[0,0.1)$ & {$[0.1,0.2]$} & $(0.2, \infty)$ \\
\hline
\end{tabular}

dzenia kropli ciekłego metalu do jeziorka.

Konieczne okazało się stworzenie algorytmów zarówno dla poszczególnych odmian spawania metodą MAG, jak i konstrukcji źródeł zasilających. Dalsze prace mają doprowadzić do stworzenia szczegółowego katalogu metod przekształcania oraz sposobów ich interpretacji, m.in. pod kątem identyfikowania niezgodności spawalniczych. 


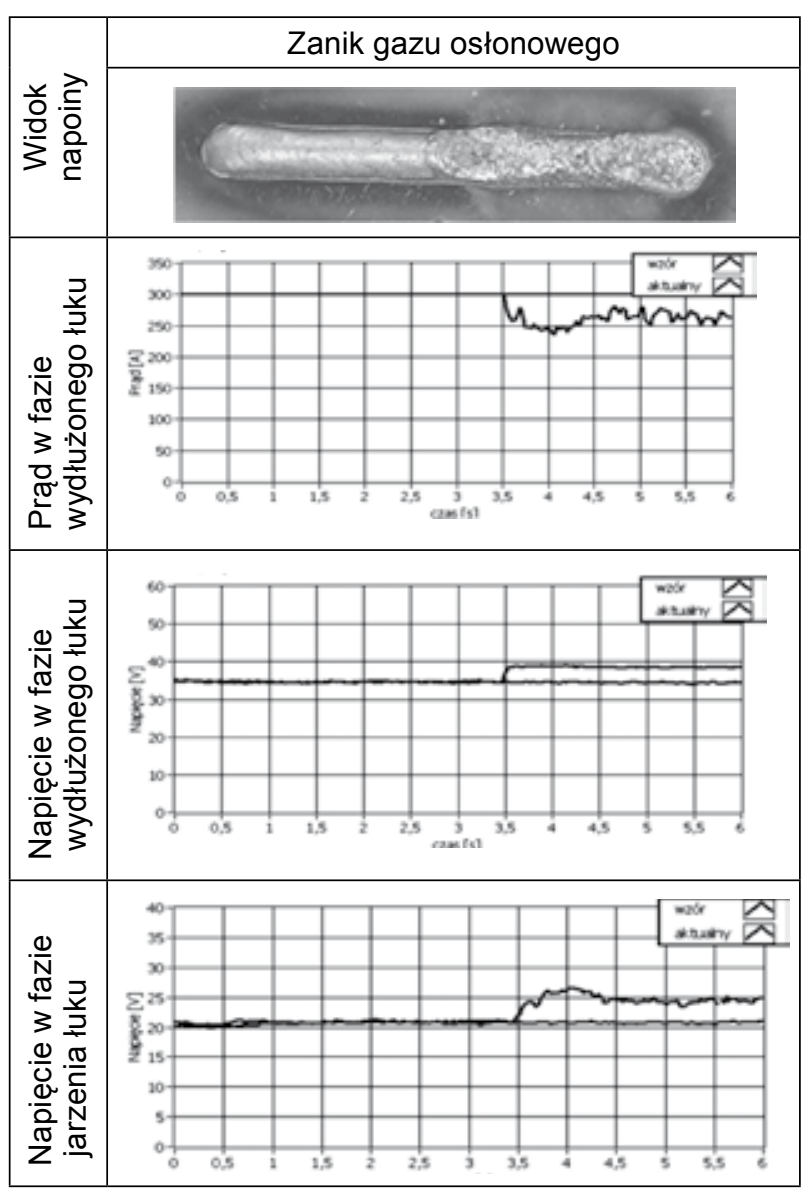

Rys. 3. Zestawienie wykresów wartości skutecznych podczas symulowanego zaniku gazu osłonowego, spawanie odmianą CMT. Przebiegi odniesiono do próby wzorcowej, niezakłóconej

Fig. 3. RMS values of current and voltage for the test with sudden lack of shielding gas, CMT welding. Waveforms compared with reference signal recorded for welding free of disturbances

\section{Literatura}

[1] Cegielski P., Kolasa A., Skrzyniecki K., Kołodziejczak P.: Komputerowy system do badań właściwości statycznych i dynamicznych źródeł energii elektrycznej do spawania łukowego. Przegląd Spawalnictwa 1/2012, s. 3-9.

[2] Cegielski P., Kolasa A.: Komputerowy system do badań właściwości statycznych i dynamicznych spawalniczych źródeł energii elektrycznej. Prace Naukowe Politechniki Warszawskiej, Mechanika, zeszyt 215, Warszawa 2006, str. 135-149.

[3] Cegielski P., Skrzyniecki K., Kolasa A., Kołodziejczak P.: Badanie stabilności układu łuk - urządzenie zasilające $w$ warunkach symulowanych zakłóceń procesu spawania metodą MAG. Przegląd Spawalnictwa 4/2013, s. 18-27.

[4] Projekt badawczy Ministra Nauki i Szkolnictwa Wyższego nr N N503 206339 pt. Badanie zależności pomiędzy zjawiskami zachodzącymi w łuku spawalniczym w różnych odmianach metody MAG a parametrami elektrycznymi układu łuk - urządzenie spawalnicze. Kierownik: prof. nzw. dr hab. inż. Andrzej Kolasa.

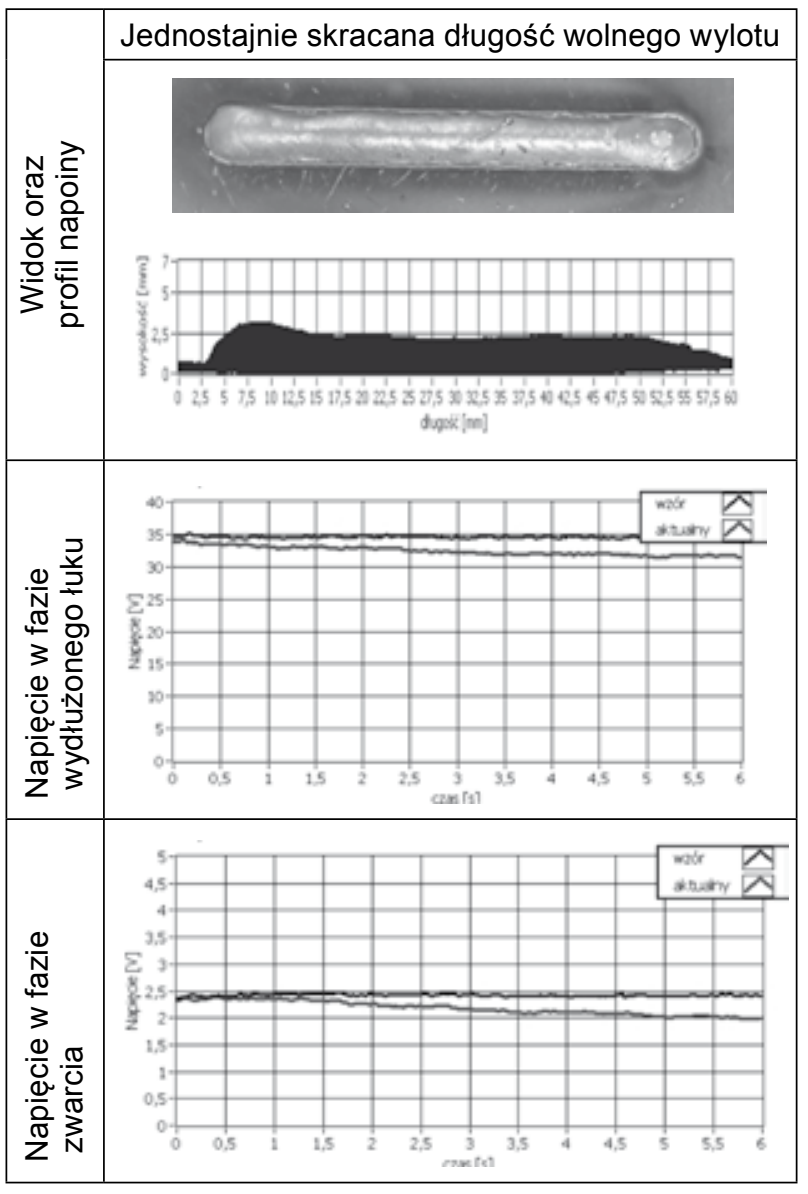

Rys. 4. Zestawienie wykresów wartości skutecznych podczas symulowanego skrócenia długości wolnego wylotu, spawanie odmianą CMT. Przebiegi odniesiono do próby wzorcowej, niezakłóconej. Fig. 4. RMS values of current and voltage for the test with decreasing the distance between the welding torch contact tube tip and the welded plate, CMT welding. Waveforms compared with reference signal recorded for welding free of disturbances.

[5] Skrzyniecki K., Cegielski P., Kolasa A., Kołodziejczak P.: Charakterystyki statyczne nowoczesnych urządzeń do spawania łukowego. Przegląd Spawalnictwa 1/2013.

[6] Skrzyniecki K., Kołodziejczak P., Cegielski P., Kolasa A.: Experimental studies on stability of power source - arc system of MAG welding processes. Proceedings of the Annual Session Of Scientific Papers, Vol. XII, IMT Oradea 2013, Rumunia, 30 May - 01 June 2013, s. 227-230.

[7] Skrzyniecki K., Krajewski A., Cegielski P., Hudycz M., Kolasa A.: Zastosowanie wirtualnych przyrządów pomiarowych do badania urządzeń i procesów spawalniczych. Prace Naukowe Politechniki Warszawskiej, Mechanika, zeszyt 229, Warszawa 2009, s. 115-124.

[8] Materiały informacyjne firm: ABB, ESAB, Lincoln Electric, IMPACT WELDING. 